Article

\title{
Comparing World Economic and Net Energy Metrics, Part 2: Total Economy Expenditure Perspective
}

\author{
Carey W. King ${ }^{1,3, *}$, John P. Maxwell ${ }^{2}$ and Alyssa Donovan ${ }^{3}$ \\ Received: 3 March 2015 ; Accepted: 29 September 2015 ; Published: 17 November 2015 \\ Academic Editor: Robert Lundmark \\ 1 Energy Institute, the University of Texas at Austin, 2304 Whitis Ave, C2400, Austin, TX 78712, USA \\ 2 Senate Fiscal Agency, P.O. Box 30036 Lansing, MI 48909-7536, USA; john.p.maxwell86@gmail.com \\ 3 Jackson School of Geosciences, the University of Texas at Austin, 2275 Speedway, C9000, Austin, \\ TX 78712, USA; alyssad13@gmail.com \\ * Correspondence: careyking@mail.utexas.edu; Tel.: +1-512-471-5468
}

\begin{abstract}
We translate between energetic and economic metrics that characterize the role of energy in the economy. Specifically, we estimate monetary expenditures for the primary energy and net external power ratio $\left(\mathrm{NEPR}_{\text {direct }}\right.$; NEPR, net external power ratio), a power return ratio of annual energy production divided by annual direct energy inputs within the energy industry. We estimate these on an annualized basis for forty-four countries from 1978 to 2010. Expressed as a fraction of gross domestic product (GDP), $f_{e, \mathrm{GDP}}$, the forty-four country aggregate (composing $>90 \%$ world GDP) worldwide expenditures on energy decreased from a maximum of $10.3 \%$ in 1979 to a minimum of $3.0 \%$ in 1998 before increasing to a second peak of $8.1 \%$ in 2008 . While the global $f_{e, G D P}$ fluctuates significantly, global NEPR direct declined from a value of 34 in 1980 to 17 in 1986 before staying in a range between 14 and 16 from 1991 to 2010. In comparing both of these metrics as ratios of power output over power input, one economic $\left(f_{e, \mathrm{GDP}}^{-1}\right)$ and one biophysical $\left(\mathrm{NEPR}_{\text {direct }}\right)$, we see that when the former divided by the latter is below unity, the world was in a low-growth or recessionary state.
\end{abstract}

Keywords: energy; net energy; economics; cost share; input-output; transition

\section{Introduction}

This manuscript is Part 2 of 3 papers comparing net energy and economic metrics. Each manuscript has similar background and motivation sections. Part 1 includes a fuller background and motivation before analyzing how net energy and power metrics translate to individual energy commodity (and technology) costs and prices, respectively [1]. Part 2 analyzes how net energy metrics relate to expenditures on energy. Part 3 places the calculations of expenditures on energy in historical, current and future contexts [2].

\subsection{Background}

Considerable debate exists surrounding the role of energy in society and the economy, and much of the disagreement stems from different methodological approaches and the time span under consideration. Conclusions range from the possible unimportance of all natural resources [3], to energy price spikes being a chief determinant of recessions [4], to energy and prime-movers as being equally important to labor and capital in driving economic growth [5,6], to energy and prime-movers as the critical elements, more important than labor or capital, in driving economies during industrialization [7] and possibly over the long term [8-10]. Countries with high per capita 
gross domestic product (GDP) tend to consume more primary energy per capita [11], even more so when considering energy embodied in imported products [12].

Access to a sufficient quantity of affordable energy and energy services is one of several important factors (e.g., also proper governance [13]) for modern living standards in an open industrial or post-industrial economy. To an economist, the prices and energy cost share are important metrics. To an ecologist and biophysical systems modeler, the energy return ratio (ERR) is an important metric for models and perspectives not purely based on monetary flows. ERRs are ratios of the energy delivered (or extracted) from an energy system divided by the energy invested to deliver that output.

While all models are wrong, some are useful. This statement is certainly poignant for energy, society and the economy. Researchers consider the role of energy in society from multiple perspectives: anthropological [14-17], economic [4,7,8,10,18-21], ecological and biophysical $[9,11,22,23]$, and others. With these different perspectives come a multitude of quantitative and qualitative methods of analysis. These analyses try to answer questions related to how energy and natural resources influence and enable societal growth, structure and organization.

While much research effort is spent on analyses to calculate ERRs of individual energy technologies and fuels for comparative analysis [24-33], there is a dearth of work linking individual ERRs to micro- or macro-economic metrics. Despite four decades since the development of the mathematical foundations in net energy analysis that relate economic accounts to country-level energy consumption [34,35], existing research has not effectively placed technology-specific net energy into the context of the broader macroeconomic modeling, economic projections and energy-economic decision-making. This disconnect serves as the motivation for this paper and other research of the corresponding author [24,36,37]. How do we relate economic and biophysical perspectives? How can we measure if affordability of energy were either acting as or indicating a constraint on economic production or growth?

We contribute data and concepts to answer these two questions at the global scale. Answering global questions requires global data, but data for global expenditures on energy are severely lacking. We provide a global dataset for expenditures on energy and net energy metrics using data from the International Energy Agency (IEA). We then translate between economic (e.g., expenditures) and biophysical (e.g., net energy) descriptions of energy. We do this by calculating and comparing metrics at the scale of individual energy commodities within a set of countries that account for the vast majority of world energy consumption and economic output.

\subsection{Part 2 Goal and Content}

The main goal of Part 2 of this manuscript series is to calculate and compare economy-wide macroeconomic metrics with net energy metrics for individual countries and the world overall. This furthers a comprehensible translation between economic and biophysical descriptions of the economy. We calculate and compare two power return ratios (PRRs) at the scale of the macroeconomy of 44 countries: one that uses information in units of money flow rates (dollars/year) and one that uses information in units of power, or energy/year.

This manuscript is organized as follows. First, Section 1.3 closes the introductory material by providing relevant background on input-output and related energy analysis mathematics. This background is useful for understanding the framework of the calculations. Section 2 describes the specific energy and economic calculations of this paper. Section 3.1 presents the time series results for expenditures on energy (an energy cost share), and Section 3.2 presents the time series of the net external power ratio (NEPR), a specific power return ratio based on units of power. NEPR is mathematically the same as what many publications refer to as "energy return on energy invested", or EROI (see King et al. [1] for the mathematical details).

Section 4 provides an interpretation of the relation between two calculated ratios: NEPR using power information and an economic net power ratio ( $\mathrm{NPR}_{\text {economic }}$ ), that is the inverse of expenditures on energy relative to GDP (or the inverse of the energy cost share). Section 4.1 discusses why 
$\mathrm{NPR}_{\text {economic }}$ is the inverse of the energy cost share and puts this in the context of data from input-output frameworks. Section 4.2 directly compares our power-based ratio of output/input, NEPR, with our monetary-based metric of output/input, NPR economic. Section 4.3 shows that that countries with high NEPR tend to be net energy exporters. Finally, Section 5 concludes the paper.

\subsection{Input-Output (I-O) Frameworks: Economic and Energy Analysis}

One goal of this paper is to understand economy-wide expenditures on energy in the context of energy and power return ratios (i.e., net energy analysis). To do this, we place our calculation of expenditures on energy in the context of input-output (I-O) accounting for both economic and net energy analysis (see Figure 1). Assume the matrix $A$ represents a technical coefficients matrix of "intermediate demands" either for the sectors of an economy, in units of money (or possibly a hybrid set of energy and money units), or a set of unit life cycle processes where each process has its own units defined by the process (e.g., tonnes of concrete). The element of $A$ in row $i$ and column $j$ is designated as $a_{i, j}$. We note that the elements of $A$ are assumed scaled such that each sector or process (described by a column) describes the inputs required to produce an output of one (e.g., one dollar or one unit from the life cycle process).

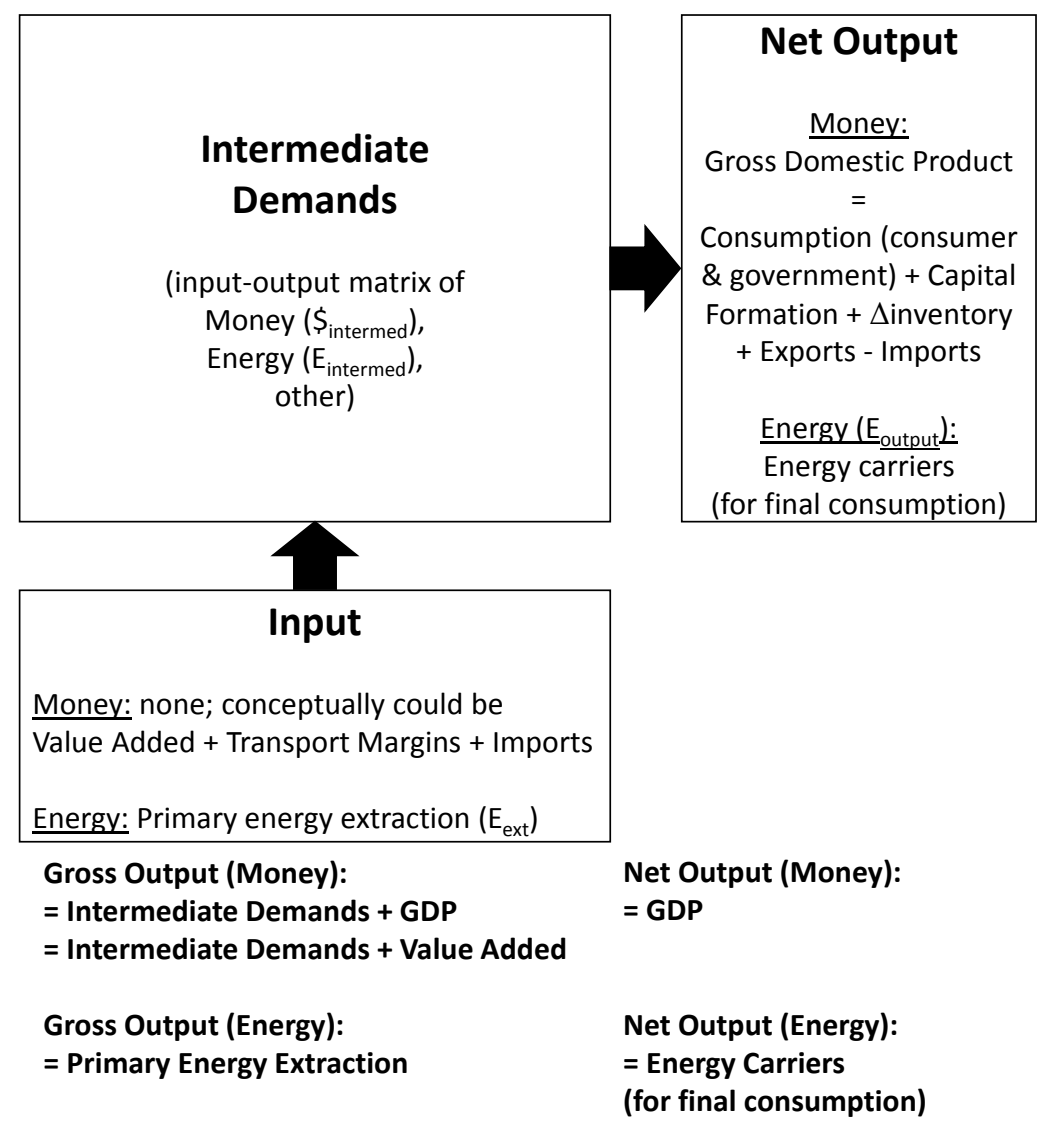

Figure 1. Input-output analysis graphic comparing terms for economic and net energy analysis. The graphic is for conceptual purposes to understand the relations between energy analysis methods and monetary I-O tables.

\subsubsection{Economic Analysis Framework}

The convention for an economic sector-by-sector I-O technical coefficient matrix, $A$, is that for a given sector, the sum of sales (sum across columns for row $j$ ) plus net output equals the sum of purchases (sum across rows for column $j$ ) plus value added [38]. Miller and Blair [38] (p. 32) go on to state: "The sum of the elements in the $j$-th column of $A$ indicates the dollars' worth of output of 
sector $j$. In an open model, given the economically reasonable assumption that each sector uses some inputs from the payments sector (labor, other value added, etc.), then each of these columns sums will be less than one $\left(\sum_{i=1}^{n} a_{i, j}<1 \text { for all } j\right)^{\prime \prime}$. This inequality usually holds because if it were not true, then it would mean that a given sector produces a dollars' output while purchasing more than a dollar of total inputs from other sectors (including itself). Miller and Blair [38] also note that this column sum condition does not generally hold for $A$ based on transactions in physical units (e.g., energy) because the mathematical convention is defined only for monetary flows.

Net output is gross domestic product (GDP). Value added (e.g., revenue left to pay salaries and have profit) is the difference in economic value between inputs purchased by a sector and products sold from that sector. While value added can conceptually be modeled as an input "from the payments sector" (as implied in from [38]), we do not use value added data for any calculations in this paper. In Section 2, we describe how we use economic I-O data to estimate energy sector purchases (inputs) that include imports.

\subsubsection{Energy Analysis Framework}

In energy analysis, the total extracted primary energy $\left(\mathrm{E}_{\mathrm{ext}}\right)$ is modeled as an input into the economy to produce output. The technological coefficient matrix $A$ describes intermediate transactions to meet an assumed demand, $Y$. The usual mathematical assumption in energy analyses using a monetary or hybrid transactions matrix, $A$, is that all primary energy, $\mathrm{E}_{\mathrm{ext}}$, input into the economy is also "embodied" in the economic net outputs, or $Y=$ GDP [34,35,39]. Thus, there is embodied energy "output" in products that we do not normally consider energy carriers (e.g., services). This embodied energy is characterized by the so-called "energy intensity", $\varepsilon$, of each process or sector.

It is common to solve for the vector(s) of energy intensities, $\varepsilon$, as in Equation (1). The $\varepsilon$ have units of gross energy extracted divided by net output where the units of the output are dictated by the units of technical coefficient matrix $A$. There are as many (non-zero) rows of $\varepsilon$ as there are primary energy resources (see [34,39-41] for details on the mathematical methods). Equation (1) uses the matrix of technological coefficients $A$; $I$ is the identity matrix; and matrix $\hat{X}$ is a matrix with the gross output of each sector along the diagonal. The inherent assumption when using a single transactions matrix is that each sector produces only one type of output product. Effectively, one solves for $\varepsilon$ independently of demand, and the total extracted energy requirement to meet an assumed demand of output, $Y$, is equal to $\varepsilon Y$. Due to the assumption of the second law of thermodynamics, energy extracted is greater than energy consumed as final demand, or $\sum E_{\text {ext }}>\sum E_{\text {output }}$ (or energy inputs $>$ energy outputs), and that $\varepsilon \geq 1$.

$$
\varepsilon=\mathrm{E}_{\mathrm{ext}} \hat{X}^{-1}(I-A)^{-1}
$$

We can use $\varepsilon$ to calculate common energy return ratios (ERRs) and power return ratios (PRRs). The gross energy ratio (GER) of the modeled system is $E_{\text {ext }}$ divided by all intermediate consumption $\left(E_{\text {intermed }}\right)$ required for that extraction [41-43]. The net energy ratio (NER) of the modeled system is total net energy output in energy carriers $\left(\mathrm{E}_{\text {output }}\right)$ divided by all $\mathrm{E}_{\text {intermed }}$ required to deliver those energy carriers to end-use consumers. GER and NER can be defined by $\varepsilon$ as follows: GER $=\frac{\varepsilon}{\varepsilon-1}$ and $\mathrm{NER}=\frac{1}{\varepsilon-1}$. Because all extracted energy that is not consumed as intermediate demand becomes net output, GER = NER +1 for a fully-modeled system with no exogenous information [41]. Furthermore, if there is zero output (equivalent to a GDP $=0$ condition), then GER $=1$ and NER $=0$ as limiting mathematical conditions.

It is important to note that inherent in the formulation of energy inputs for NER is the inclusion of energy losses from feedstock conversions (e.g., dissipated heat from burning fuel in a power plant). Other ERRs that do not include dissipated energy from feedstocks are very important for use to compare life cycles of individual technologies (various EROI metrics in [33], $\mathrm{EROI}_{\text {pou }}$ and $\mathrm{EROI}_{3}$ in [44], net external energy ratio (NEER) in [1,41-43] and the energy payback ratio (EPR) of [45]). 


\subsubsection{I-O Frameworks Compared: Money Ratios Compared to Energy and Power Return Ratios}

Here, we provide some background on the differences between energy analysis methods that use monetary I-O frameworks and the monetary I-O frameworks themselves. This background is important when we later compare our economy-wide net energy metric to that of Herendeen [46] in Section 4.1 .

In energy-based net energy analyses, the second law of thermodynamics is employed in the form of energy conversion efficiencies, $\eta$, less than one (see [41] for an example calculation). Mathematically, $\eta<1$ means that in the energy-based technical coefficients matrix, $A$, the off-diagonal coefficient, say $a_{1,2}$, is $>1$ when it represents how much output from a primary energy extraction process (Process 1) is required as input into an energy conversion process (Process 2) to produce an energy carrier using that Process 1 primary energy as a feedstock. For example, a coal-fired power plant (process) converting coal into electricity might intake $1 \mathrm{MJ}$ of coal primary energy and output $0.4 \mathrm{MJ}$ of electricity (e.g., $\eta=0.4$ ). Thus, one unit of net output electricity requires at least $1 / \eta=1 / 0.4=2.5$ units of coal primary energy, and the relevant technical coefficient $a_{1,2}=2.5>1$. In his simplified two-sector model of the economy, Herendeen [46] does not model separate energy extraction and conversion sectors, and this has implications for his calculated economy-wide EROI, which we term the gross power ratio (GPR) (see Section 4.1 and Section 2.1 of King et al. [1]). Thus, he has an on-diagonal energy-based technical coefficient that is less than one: $a_{1,1}=a_{e, e}<1$. In essence, the assumption is that extracted energy is consumed by consumers in the same form at which it comes from the environment.

While it is required to have a coefficient, $a_{1,2}>1$, in an energy-based technical coefficients matrix describing an energy extraction Process 1 and an energy conversion Process 2, this is not the case for a monetary-based coefficients matrix, $A$ [38]. An energy conversion business needs to purchase $\$ 1$ worth of fuel to produce $\$ 2.5$ of net output even though it might purchase $2.5 \mathrm{MJ}$ of fuel to sell $1 \mathrm{MJ}$ of an energy carrier. Table 1 shows a simplified construction of an I-O table with only one sector. The equivalent version of Equation (1) for a pure monetary I-O matrix $A$ is as in Equation (2), where instead of an input as $\mathrm{E}_{\mathrm{ext}}$, the input is assumed as the payment vector, $p$ [46].

Table 1. A one-sector I-O model demonstrates the normal assumptions for the construction of an I-O table with intermediate transactions matrix $Z$, net output $Y$ and gross output $X$. Note: $a_{1,1}=z_{1,1} / X_{1}$.

\begin{tabular}{lccc}
\hline & $\begin{array}{c}\text { Process } \\
\text { Sector }\end{array}$ & $\begin{array}{c}\text { Final } \\
\text { Demand }\end{array}$ & $\begin{array}{c}\text { Total } \\
\text { Output }\end{array}$ \\
\hline Process Sector & $z_{1,1}$ & $Y_{1}$ & $X_{1}=z_{1,1}+Y_{1}$ \\
Payments Sector & $p_{1}$ & $d_{1}$ & $p_{1}+d_{1}$ \\
Total Outlays & $X_{1}=z_{1,1}+p_{1}$ & $Y_{1}+d_{1}$ & $X_{1}+Y_{1}=X_{1}+p 1$ \\
\hline & $\varrho=p \hat{X}^{-1}(I-A)^{-1}$ &
\end{tabular}

Because of the monetary I-O convention (e.g., for a given sector, the sum of rows including value added equals the sum of the columns including GDP [38]) in Table 1, a money intensity, $\varrho$, in units of gross money input over net money output, does not vary like the energy intensity, $\varepsilon$, described before. Equation (3) shows that $\varrho=1$ always. We can then calculate a mathematical equivalence to GER, a "gross money ratio" (GMR), and NER, a "net money ratio" (NMR), using an economic I-O model. However, because economic money intensity is one, $\varrho=1$, by convention of the I-O formulation, both GMR and NMR are infinity: GMR $=\frac{\varrho}{\varrho-1}=\frac{1}{1-1}=\frac{1}{0}$ and NMR $=\frac{1}{\varrho-1}=\frac{1}{1-1}=\frac{1}{0}$ ). 


$$
\begin{aligned}
\varrho & =p \hat{X}^{-1}(I-A)^{-1} \\
& =p_{1}\left(\frac{1}{X_{1}}\right)\left(1-a_{1,1}\right)^{-1} \\
& =p_{1}\left(\frac{1}{z_{1,1}+p_{1}}\right)\left(1-\frac{z_{1,1}}{z_{1,1}+p_{1}}\right)^{-1} \\
& =\left(\frac{p_{1}}{z_{1,1}+p_{1}}\right)\left(\frac{z_{1,1}+p_{1}-z_{1,1}}{z_{1,1}+p_{1}}\right)^{-1} \\
& =\left(\frac{p_{1}}{z_{1,1}+p_{1}}\right)\left(\frac{z_{1,1}+p_{1}}{p_{1}}\right) \\
& =1
\end{aligned}
$$

Thus, there is no mathematically-equivalent manner to compare energy and economic I-O constructions based on an assumption that the payments sector (or value added) is an input and total output is GDP plus intermediate transactions. By definition, in economic I-O formulations for each sector, the sum of all intermediate purchases plus value added equals the sum of intermediate sales plus net output [38], but the assumption is completely different for energy analysis that assumes a separate exogenous input of energy. Further, economic I-O tables typically have total intermediate transactions of equivalent magnitude as total net output, or GDP. That is to say, for most I-O tables, the sum of all elements in the intermediate demands matrix is often approximately equal in magnitude to GDP (e.g., $\sum_{i} \sum_{j} z_{i, j} \sim \sum_{i} Y_{i}$ ). Thus, one could define this as a "gross output ratio" (GOR) as total gross monetary output (e.g., GDP plus intermediate sales) flows divided by all intermediate flows. For most countries, this number is $\sim 2$ (see the World Input-Output Database (WIOD) tables [47]). A similarly-defined "net output ratio" (NOR) equal to GDP divided by all intermediate flows is typically $\sim 1$, or NOR $=\mathrm{GOR}-1$.

\section{Methods}

\subsection{Definitions of Energy and Power Return Ratios}

In Part 1 of this paper, we discussed extensively the definitions and differences among various metrics used in net energy analysis [1]. We refer the reader to that paper, and its references, for details on terminology.

The most important concept for interpreting the results and discussion of this paper, Part 2, is that all metrics and data inherently derive from power data, or energy flows over time (e.g., MJ/year). Thus, we use the terminology of power return rations (PRRs) rather than energy return ratios (ERRs). Specifically in this Part 2, we use net power ratio (NPR) and net external power ratio (NEPR). A common term for our NEPR is energy return on energy invested at the point of use $\left(\mathrm{EROI}_{\mathrm{pou}}\right)$ (e.g., [28]).

\subsection{Monetary Expenditures on Energy}

We undertake the calculations in this paper because the IEA provides a rich database of energy prices and consumption. The data span dozens of countries and years. To our knowledge, no one has used these data to estimate expenditures for energy, calculate energy and power return ratios or interpret these energy and economic data in the context of net energy.

\subsubsection{IEA Data}

The vast majority of effort was to organize the price and consumption data used for the calculations of this manuscript. The data were purchased from the IEA Beyond 20/20 Global Database for nine aggregated energy commodities from 28 individual commodity prices. We convert all IEA energy prices and GDP from nominal U.S. dollars to constant 2005 U.S. dollars 
(\$2005). We use the price deflator from the Energy Information Administration Appendix D of the Annual Energy Review to convert data in nominal dollars to constant \$2005. The oil price is the first import price, and all others are as indicated for the particular end-use sector. Except for oil and refined oil, we use prices from the IEA Energy Prices and Taxes dataset that include taxes. We refer the reader to the Supplemental Information for details on our use of IEA data. The 44 countries within the IEA dataset compose approximately 93\%-95\% of world GDP and 73\%-79\% of the IEA's listed world Total Primary Energy Supply (TPES) (>78\% after 1994) from 1978-2010. The 44 countries with data in the IEA database are: the United States, the United Kingdom, Spain, Russia, the Netherlands, Japan, Italy, Germany, Canada, France, Austria, Denmark, Finland, Norway, Sweden, Argentina, Australia, Belgium, Brazil, China, Chinese Taipei, Colombia, Czech Republic, Greece, Hungary, India, Indonesia, Iran, Iraq, South Korea, Kuwait, Libya, Malaysia, Mexico, New Zealand, Nigeria, Poland, Portugal, Qatar, Saudi Arabia, South Africa, Switzerland, Turkey and Venezuela.

Monetary expenditures on energy for each country are equal to the sum of price $\left(p_{n}\right)$ multiplied by the quantity purchased $\left(c_{n}\right)$ by three sectors (industrial, electricity and residential) for natural gas and coal (coal consumption aggregated from 5 separate coal types), two sectors for electricity (industrial and residential) and oil (aggregated from five petroleum feedstock types and 3 refined products of gasoline, diesel and fuel oil). We use annual prices that, per the IEA, are twelve-month average prices from monthly-reported prices to the IEA. Thus, the average price does not account for weighting based on the amount of consumption that occurs each month. The energy prices include transport costs to the consumer; they are prices actually paid (i.e., net of rebates); they include taxes that have to be paid by the consumer as part of the transaction and which are not refundable. For summing various expenditures on energy, we avoid double-counting fossil energy consumption that was used to generate electricity by reducing the expenditures on electricity for each country by the fraction of electricity supplied by fossil fuels. We approximate expenditures on electricity from nuclear power plus renewable resources, such as hydropower and wind, that are often considered "primary energy", and we term this "non-fossil" electricity (see Figure 2). We consider expenditures on oil separately from end-use sectors, such that we do not double-count oil consumed when generating electricity in a thermal power plant. Thus, our total expenditure on energy is the sum of expenditures for oil, coal, natural gas and non-fossil electricity and does not include $100 \%$ of expenditures on electricity (see the Supplemental Information for details).

We calculate expenditures on energy as a fraction of GDP, $f_{e, \mathrm{GDP}}$, as a useful metric for understanding the scale of intermediate (non-consumer) energy expenditure relative to the total output of the overall economy (Equation (4)). Ideally, we would not calculate any consumer expenditures on energy. However, because of the format of the IEA price data, we actually calculate a mixture of intermediate and consumer energy expenditures because of the existence of residential prices for coal, natural gas and electricity.

In order to maintain mathematical consistency, we calculate only expenditures of individually-listed energy commodities to which we can match a price. In summing energy consumption across all commodities that we use to calculate expenditures on energy, we slightly underestimate TPES at $87 \%-93 \%$ relative to that reported by the IEA (see the Supplemental Information for more details, Figure S4). For example, we do not estimate TPES or expenditure contributions from biomass and other non-marketed energy goods (e.g., consumed for subsistence). We expect this underestimate of TPES translates to an underestimate of $f_{e, \mathrm{GDP}}$.

$$
f_{e, \mathrm{GDP}}=\frac{\text { expenditures on energy }}{\mathrm{GDP}}=\frac{\sum_{n=1}^{9} p_{n} c_{n}}{\mathrm{GDP}}
$$

In some cases, energy consumption data for a certain commodity and country are not in the data, and in these cases, we do not calculate a value that contributes to "actual data" expenditures on energy. We calculate the "estimated" expenditures in Figure 2 by inputting a reasonable (e.g., data 
from a nearby country) energy price estimate when there are missing price data. See the Supplemental Information for full details on the price substitution for our "estimated" expenditures on energy. We also include a "high world prices" and "low world prices" calculation for expenditures on energy to provide cases where the lowest/highest price in the dataset for each commodity each year is applied to all countries. We see the "high world prices" and "low world prices" estimates as the most practical way to understand the possible range of our calculation, and they should be compared to our "estimated" calculation instead of the "actual data" calculation that is by definition incomplete due to some missing data.

World Energy Expenditures as fraction of GDP (\%)

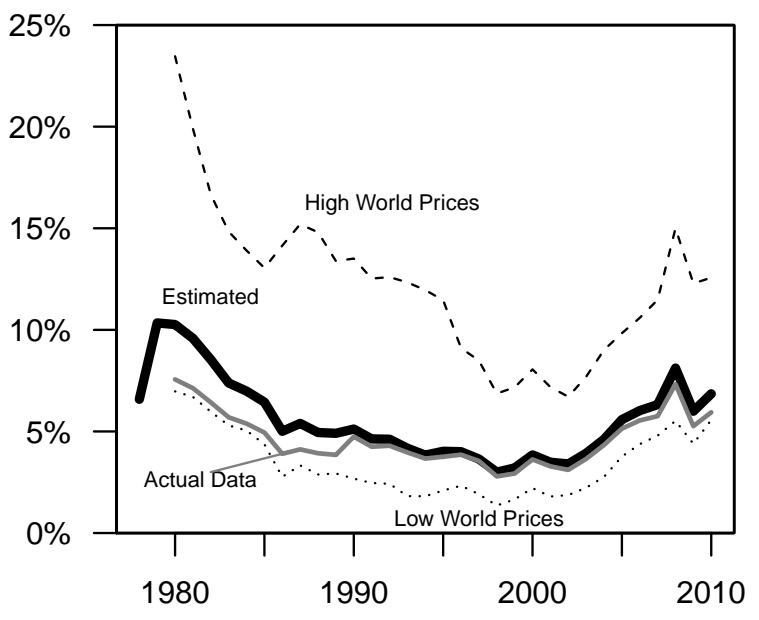

(a)

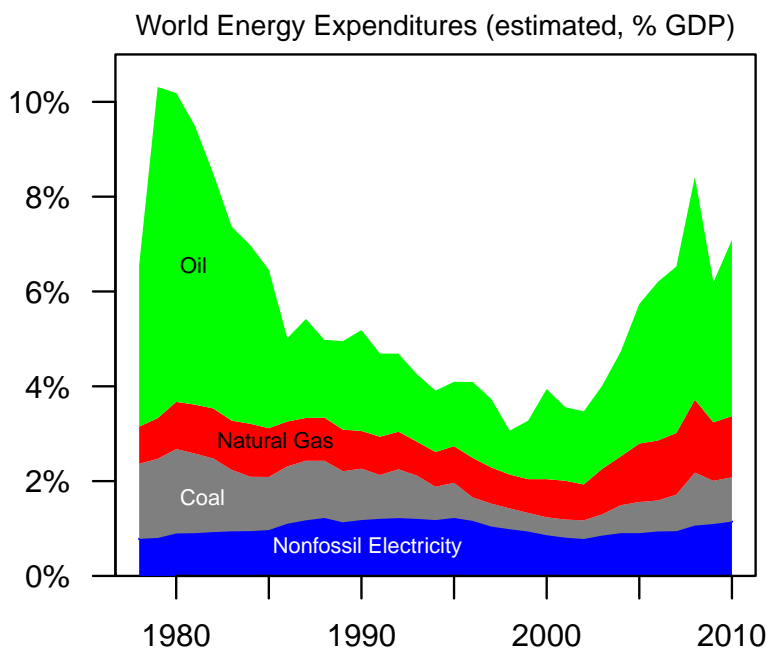

(b)

Figure 2. (a) Total energy expenditures divided by GDP, $f_{e, \mathrm{GDP}}$, for the 44 countries in the dataset from 1978-2010; (b) expenditures on energy divided by GDP, $f_{e, G D P}$ (for the 44 countries in the dataset), per commodity, using the "estimated" calculation. Actual data = using "actual" data as reported in the IEA dataset (no substitutions for missing data). Estimated = assumes prices for countries with no price data for certain commodities (see the Supplemental Information). "Low/high world prices" = assumes the lowest/highest price in the dataset for each commodity in each year is applied to all countries. 
2.2.2. Estimating Intermediate Expenditures on Energy from I-O Tables (World Input-Output Database)

One task of this paper is to compare our $f_{e, \text { GDP }}$ derived from IEA data to an equivalent (as much as possible) calculation using information from the World Input Output Database (WIOD). The WIOD includes harmonized I-O tables, composed of 35 sectors, for 28 of the 44 countries in our IEA dataset (see the Supplemental Information for a list of countries in each dataset).

We consider three of the 35 WIOD industrial sectors as "energy" sectors: mining and quarrying; coke, refined petroleum and nuclear fuel; and electricity, gas and water supply. These sectors both exclude some aspect of energy sector transactions and include some non-energy transactions. The construction of the WIOD is based on the EU KLEMSframework, which does define subsectors that distinguish between energy and non-energy contributions in the above three sectors $[48,49]$. The mining and quarrying sector has two subsectors that distinguish energy producing materials from other materials. The electricity, gas and water supply is also decomposed into its three components (electricity, gas, water), such that water supply costs can be excluded. As an example for mining and quarrying for the year 2007 for Germany and the U.K., approximately $70 \%$ of mining and quarrying expenditures were associated with energy-producing materials. However, the underlying source economic data are not the same for all countries, and this prevented the the creators of the WIOD from disaggregating our chosen 3 WIOD sectors into the more informative energy-only subsectors for all countries in the WIOD.

We estimate intermediate expenditures, or intermediate demand purchases, by the 3 energy sectors in the WIOD as the sum of all of their intermediate spending plus gross capital formation (GCF). Our goal is for $f_{e, G D P}$ to be an estimate of intermediate spending on energy and not consumer spending on energy. In this way, spending on energy is an input to the energy sub-system and GDP is the total output of the entire economy. Our goal is not to consider the output (e.g., part of GDP) associated with these three sectors and relate that to total GDP.

\subsection{Direct Energy Input PRRs}

In addition to energy price, production and consumption data, other IEA data enable the calculation of a purely physical power return ratio (PRR). In most of the existing net energy literature, our PRRs described in this section would be termed as EROI or some other terminology that includes the word energy instead of power. We refer the reader to Part 1 [1] of this manuscript series for the details on why it is important to distinguish between ERRs (energy output divided by energy invested) and PRRs (power output divided by power invested).

Here, we use country annual energy production as the power output and "energy industry own use" (EIOU) data as reported by the IEA as the invested input power. The IEA documentation states that "Energy industry own use covers the amount of fuels used by the energy producing industries (e.g., for heating, lighting and operation of all equipment used in the extraction process, for traction and for distribution)." Further, the EIOU does not include fuel inputs into transformation processes (e.g., coal burned to produce electricity). Thus, to maintain consistency with the previous PRR definitions (see Part 1 [1]), our use of EIOU data enables us to calculate the gross external power ratio (GEPR) and net external power ratio (NEPR), not the gross power ratio (GPR) or net power ratio (NPR), because there is no feedstock fuel counted as input. Therefore, for each country, power production divided by EIOU calculates the gross external power ratio considering only direct power inputs, GEPR direct, country (see Equation (5)). The net external power ratio, NEPR direct, country, subtracts EIOU from the numerator of GEPR direct, country. The theoretical minimum values for GEPR and NEPR are 1 and 0 , respectively. That is to say, the energy sector cannot consume more power than it extracts. Practically speaking, a given country's energy sector can consume more power (or energy) than it extracts by importing power (or energy). 


$$
\begin{gathered}
\text { GEPR }_{\text {direct, country }}=\frac{\text { Annual Energy Production }_{\text {country }}}{\text { Annual EIOU }_{\text {country }}} \\
\mathrm{NEPR}_{\text {direct, country }}=\frac{\text { Annual Energy Production }_{\text {country }}-\text { Annual EIOU }_{\text {country }}}{\text { Annual EIOU }_{\text {country }}}=\text { GEPR }_{\text {direct, country }}-1
\end{gathered}
$$

We use the subscript "direct" in order to maintain consistency with the net energy literature and to provide clarity to the reader. Direct power and energy investments are those in the form of fuels and energy carriers, such as gasoline and electricity. Indirect power and energy investments are inputs, converted to units of power or energy (e.g., MJ), but for which the investment data exist with other physical units (e.g., kg, liters) or monetary units (e.g., \$ for services). The direct plus indirect energy inputs are termed the embodied energy [34,35].

The numerator of $\mathrm{GEPR}_{\text {direct }}$ is composed of the listed annual energy production sources of crude oil, natural gas liquids (NGL), natural gas (NG), coal and the heat equivalents for electricity from nuclear, solar, hydropower and pumped hydropower, wind, geothermal and tidal power. The

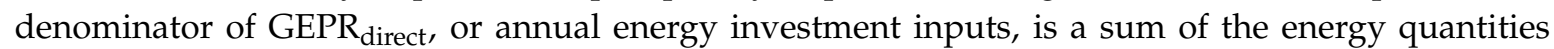
listed in the EIOU data. The energy commodities in EIOU include the aforementioned ones for energy production in addition to secondary energy sources, such as refinery feedstocks and refined products, bitumen, petroleum coke and others. We calculate worldwide metrics for our 44-country

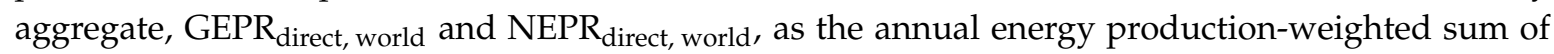
all GEPR direct, country $_{\text {and NEPR }}$ direct, country, respectively. Due to data limitations, the time series from 1960-1979 includes fewer countries than from 1980-2010. See the Supplemental Information for full details on the assumptions for calculating EIOU, GEPR direct $_{\text {and }}$ EPPR $_{\text {direct }}$.

\section{Results}

The major results are as follows, with more detail in the rest of this section:

- The estimated $f_{e, \mathrm{GDP}}$, using IEA data, decreased from a maximum of $10.3 \%$ in 1979 to $3.0 \%$ in 1998 before increasing to $8.1 \%$ in 2008 .

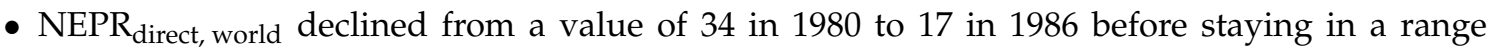
between 14 and 16 from 1991-2010.

\subsection{Expenditures on Energy/GDP $=f_{e, G D P}$}

Figure 2 shows "worldwide" expenditures on energy as a fraction of GDP $\left(f_{e, \mathrm{GDP}}\right)$ for the 44-country aggregate. Figure 3 indicates worldwide expenditures on energy for each of the nine energy commodities.

The estimated $f_{e, \mathrm{GDP}}$ decreased from a maximum of $10.3 \%$ in 1979 to $3.0 \%$ in 1998 before increasing to $8.1 \%$ in 2008 . The two peaks in this percentage are associated with the two periods of highest oil prices and lowest worldwide economic growth since World War II [50]. During the time periods of lowest economic growth and highest $f_{e, \mathrm{GDP}}$, the monetary expenditures for oil are larger than for all other energy combined (see Figures 2 and 3).

Note that the actual and estimated totals in Figure $2 \mathrm{a}$ are not exactly equal to the sum of expenditures on the nine individual commodities in Figure 3 to avoid double-counting fossil fuels used for electricity generation. Figure $2 b$ shows estimated expenditures on energy per the four major commodity categories. 

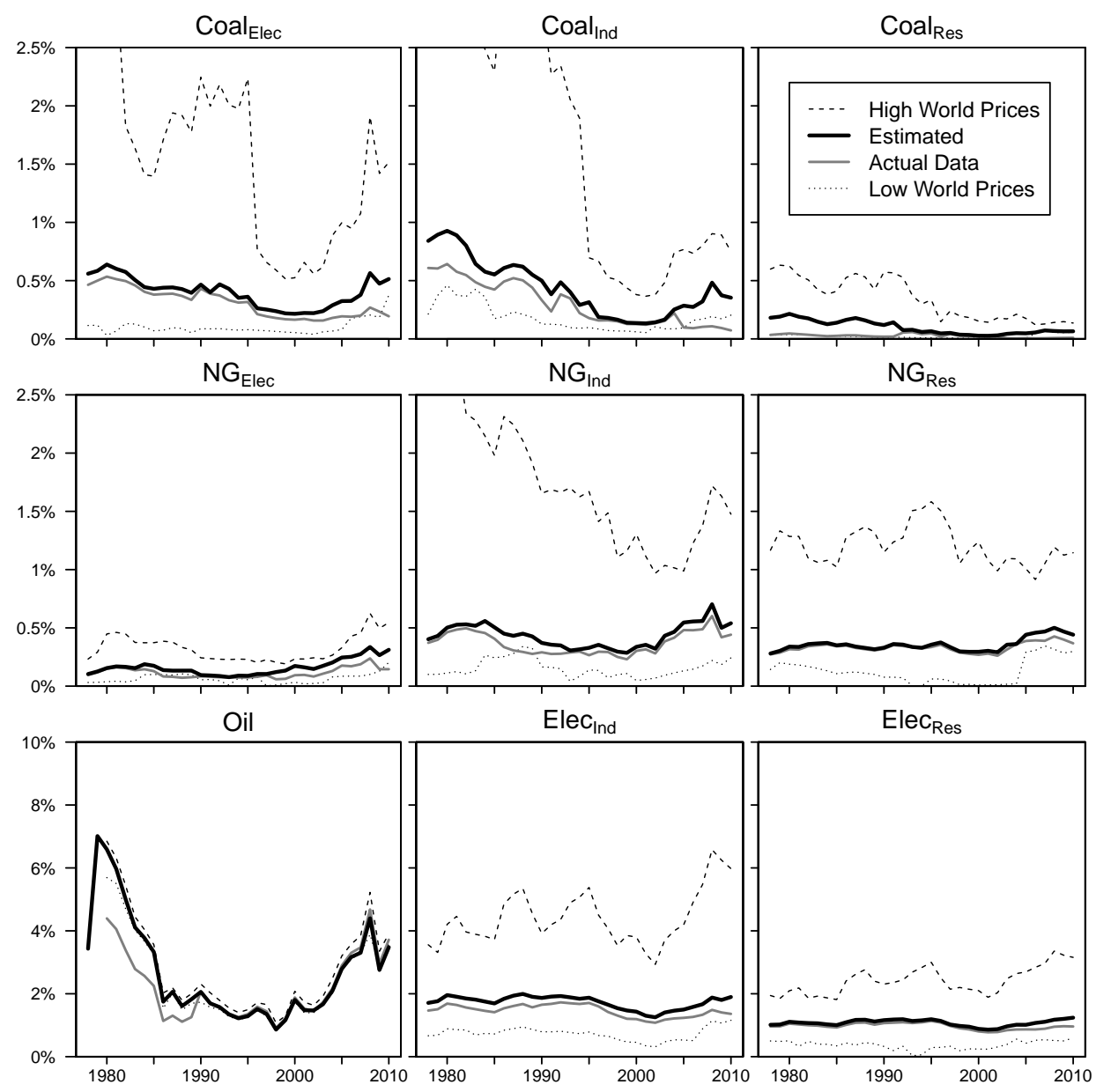

Figure 3. The expenditures on energy for the aggregate 44 countries in the dataset as a percentage of GDP $\left(f_{e, \mathrm{GDP}}\right)$ for each of the nine major energy commodities. Estimated = assumes reasonable prices for countries with no price data for certain commodities. Low / high world prices = assumes the lowest/highest price in the dataset for each commodity is applied to all countries. Actual data = calculation using available data in IEA dataset with no substitutions. For some years and commodities, the low world prices calculation is greater than the actual dataset because sometimes, there are no "actual" price data. Thus, one calculates zero expenditures for that country, year and commodity, and when applying the low world prices' (non-zero) worldwide price to this situation, the energy expenditure is now greater than zero. $\mathrm{NG}=$ natural gas, Elec = electricity, Ind = industrial and $\operatorname{Res}=$ residential, such that, for example, $\mathrm{NG}_{\text {Ind }}$ is natural gas purchased by the industrial sector.

The Supplemental Information spreadsheet lists $f_{e, \mathrm{GDP}}$ for each country and each commodity, as well as for the aggregated 44 countries. See Supplemental Figures S1 and S2 for a plot of the $f_{e, \mathrm{GDP}}$ for each country over time.

\subsection{NEPR direct}

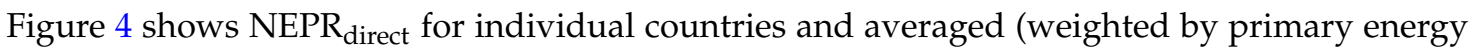
production) for two world aggregates. The dashed red line (from 1960 to 2010) includes data from the 26 OECD countries in our dataset, and the solid red line (from 1980 to 2010) includes data from all 44 countries in the dataset. The 26-OECD average $\mathrm{NEPR}_{\text {direct }}$ changes very little over each separate time period. It varies between eight and 10 from 1960 to 1979 and between 10 and 13 from 1980 to 2010, with the maximum NEPR direct $=12.9$ in 2002 dropping to 10.7 in 2010. 


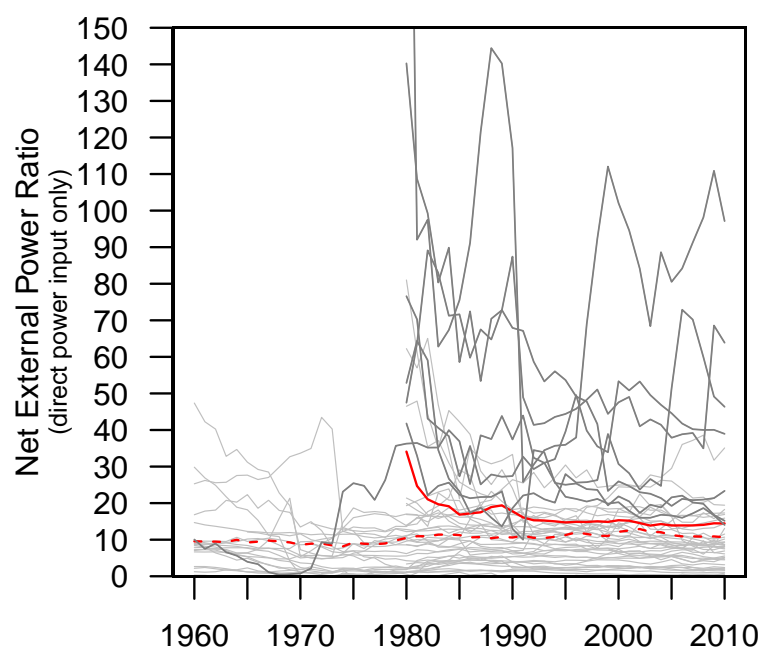

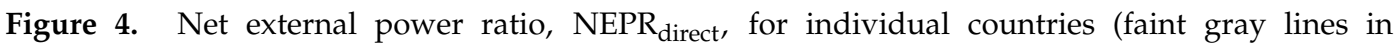
background) and the weighted world average (solid red line: the energy production-weighted "world" average for all 44 countries from 1980 to 2010; dashed red line: for the 26 OECD countries continuous from 1960). Dark gray lines represent several oil and gas exporting countries (Saudi Arabia, Nigeria, Iran, Iraq, Kuwait, Norway and Libya). Due to data limitations, we cannot estimate NEPR $_{\text {direct }}$ from 1960 to 1979 for the non-OECD countries (see the Supplemental Information).

The post-1980 data include all 44 countries in our IEA dataset, and the three years 1980 to 1982 have the largest values of 34,25 and 21 , respectively. The 44-country NEPR direct,world is less than 20 from 1983 to 2010. From 1983, this power return ratio declined to 17 in 1985, rose to 19 in 1989 and dropped to 15 in 1995. From 1995 to 2010, the 44-country NEPR direct,world is generally between 14 and 15 with 2005-2007 having the minimum values of the time series of 13.9 before a very slight rise to 14.4 in 2010. We do not know if our 1980-1982 calculations of NEPR direct,world $>20$ are due to underlying data consistencies or if there was indeed such a dramatic drop in NEPR $\mathrm{direct,world}_{\text {during }}$ that time. Further research is needed to interpret these high $N_{E P R}$ direct,world.

Most individual countries exhibit relatively constant $\mathrm{NEPR}_{\text {direct }}$ over time. Some major exceptions are indicated in bold gray lines in Figure 4. These countries primarily correspond to crude-oil exporting countries, many of whom also have relatively large $\mathrm{NEPR}_{\text {direct }}$ (e.g., $\left.\mathrm{NEPR}_{\text {direct, oil exporter }}>\mathrm{NEPR}_{\text {direct, world }}\right)$. We explore this relationship in Section 4.3.

\section{Discussion}

\subsection{Context of $f_{e, G D P}^{-1}$ as Economy-Wide Power Return Ratio, NPR economic}

Here, we compare our calculation of $f_{e, \mathrm{GDP}}$ using the IEA data to a similar calculation using the I-O tables of the World Input Output Database (WIOD). For the 28 common countries in both the IEA and WIOD data, the direct intermediate spending (e.g., sum of all purchases, or rows in the I-O table, plus gross capital formation, GCF) by the three energy sectors is the upper dashed line of Figure 5 and generally larger (by $\sim 1 \%$ of GDP) than our IEA-based calculation. We calculate GDP from the WIOD as "total output" minus "total intermediate consumption", with the latter including imports. The portion of net output, or GDP, associated with these three energy sectors ( $<2.5 \%$ of GDP each year) is relatively low compared to our calculations for expenditures on energy. For comparative purposes, we also perform the same WIOD calculations for the U.S. only (described in Supplemental Information Figure S3). The U.S. is a good example because it has relatively low taxes on energy and shows a much closer match to our IEA-based $f_{e, \text { GDP }}$ to WIOD intermediate energy sectors' spending.

To compare economic energy-sector intermediate spending plus gross capital formation (GCF) in the context of net energy boundary conditions, we consider these three energy sector intermediate 
purchases as conceptually equivalent to intermediate energy consumption, $E_{\text {intermed }}$. Similarly, GDP is conceptually similar to $E_{\text {output, }}$ because all extracted primary energy, $E_{\text {ext }}$, is assumed embodied in all net outputs. Therefore, we calculate an economic economy-wide metric equal to GDP divided by the intermediate purchases plus GCF of the three energy sectors, as

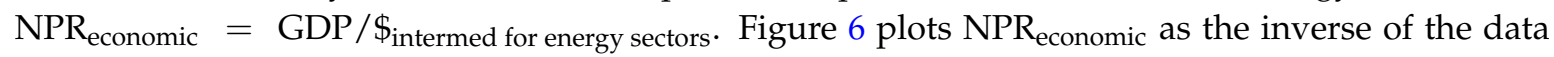
in Figure 5.

We subscript this calculation as "economic", NPR economic, to distinguish it from a power-based NPR calculation. Economic I-O tables typically have feedstock extraction sectors (e.g., oil and gas extraction, coal mining) and conversion sectors (e.g., electric utilities). However, within economic I-O tables, there is no concept of a "feedstock" of money or the second law of thermodynamics, such that ERRs and PRRs are not well defined using pure monetary data from the I-O tables. For example, for every one unit of feedstock fuel into a power plant, only a fraction, $\eta$, is converted to electricity, and this fraction is known based on the operating conditions via thermodynamic principles. In contrast, for every one unit of money spent on feedstock fuel, there is no single known amount of money earned from selling the electricity, as it depends on various factors, such as the regulatory and market (e.g., supply and demand) situation in which the power plant operates. Early net energy researchers recognized this problem and replaced the monetary output flows of the energy sectors in the I-O table with energy flow data $[34,39,40]$. In effect, they created hybrid I-O tables with both energy and monetary units.

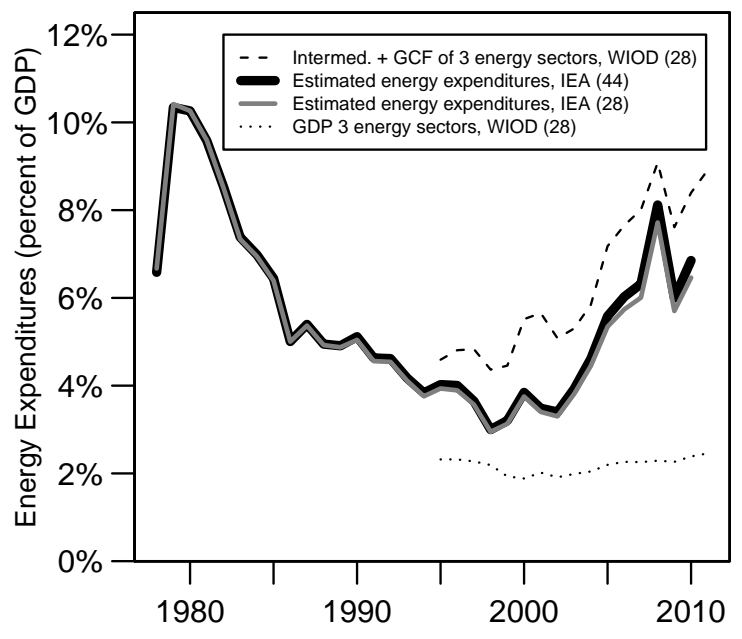

Figure 5. A comparison of expenditures on energy relative to total GDP for the world shows that the calculation in this paper most closely matches intermediate expenditures in the three energy sectors of the WIOD rather than the portion of GDP associated with those three energy sectors. "Intermed" = intermediate spending of the three energy sectors, and "GDP 3 energy sectors" = the portion of GDP for the three energy sectors. WIOD = uses data in World Input Output Database; IEA = uses IEA data as calculated in this manuscript; $44=$ calculations include data from all 44 countries in our IEA dataset; and 28 = calculations include only 28 countries in both WIOD and IEA datasets. 


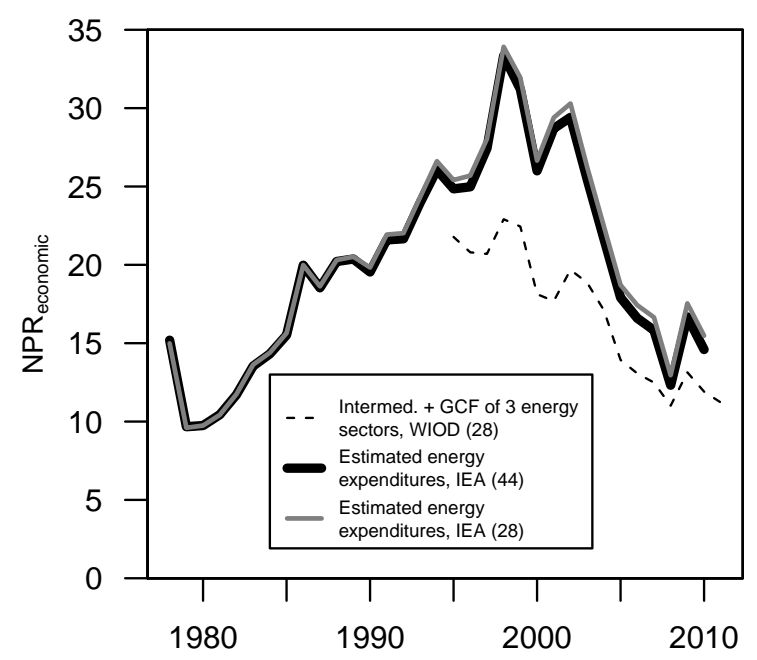

Figure 6. The trends are similar for both the economic-based net power ratio of the world economy calculated as $\mathrm{NPR}_{\text {economic }}=f_{e, \mathrm{GDP}}^{-1}$ using IEA data in this paper and $\mathrm{NPR}_{\text {economic, } \mathrm{WIOD}}=\mathrm{GDP} /$ (intermediate energy sector spending), assuming the three WIOD energy sectors intermediate ("Intermed") spending. WIOD = uses data in World Input Output Database; IEA = uses IEA data as calculated in this manuscript; $44=$ calculations include data from all 44 countries in our IEA dataset; and 28 = calculations include only 28 countries in both WIOD and IEA datasets.

It is useful to contrast $\mathrm{NPR}_{\text {economic }}=f_{e, \mathrm{GDP}}^{-1}$ with the economy-wide EROI calculated by Herendeen [46]. Herendeen [46] calculates what he terms an EROI of the 2007 U.S. economy using a highly aggregated hybrid energy and a monetary I-O table with only two sectors (two sectors: $e=$ energy sector, $m=$ machinery sector equal to all others). The single energy sector, $e$, has an energy self-use coefficient $a_{e, e}=0.297$ that is necessarily greater than zero (e.g., intermediate energy sector processes dissipate some energy due to the laws of thermodynamics). He calculates economy-wide EROI $(=3.25)$ of the primary energy using the mathematics that relate to the gross power ratio ([1]), GPR $=\frac{\varepsilon}{\varepsilon-1}$, and the gross energy ratio, GER as in [41]. We say that Herendeen calculates GPR rather than GER because it is based on annual flows of power and money for the single year 2007, not energy and money integrated over time. Further, if the only non-zero energy or monetary transaction is $a_{e, e}$ (e.g., $a_{e, m}=a_{m, e}=a_{m, m}=0$ ), then Herendeen's "EROI" = our GPR $=3.37$. This value is the upper limit GPR assuming only an efficiency of the energy sector passing energy to consumers $\left(\eta=1-a_{e, e}=0.703\right)$ to calculate $\mathrm{GPR}_{\text {upper limit }}=\frac{1 / \eta}{1 / \eta-1}=\frac{1}{a_{e, e}}=3.37$ [41]. Hence, the other three transactions in Herendeen's $2 \times 2$ hybrid I-O matrix have relatively little influence over the return ratio calculation. Herendeen [46] notes that his EROI is "fortuitously" similar to that calculated by weighting results from Hannon et al. (1985) as "EROI" = GPR $=3.32$ for the 1977 U.S. economy. However, this similarity is a function of the underlying reality that the energy sectors consume approximately $30 \%$ of extracted primary energy while sending the other $70 \%$ for consumption by others (e.g., consumers, government and intermediate sectors). Perhaps it is not a coincidence that also $\sim 65 \%-70 \%$ of GDP is composed of consumer spending (e.g., per WIOD data for the United States), but that remains an area for future research.

\subsection{NEPR $R_{\text {direct }}$ Relative to $f_{e, G D P}^{-1}$}

Previously, we described economy-wide $\mathrm{NPR}_{\text {economic }}=f_{e, \mathrm{GDP}}^{-1}$, and in this section, we ask how this metric compares to that of $\mathrm{NEPR}_{\text {direct }}$ in Figure 4. Is there any relationship we should expect between an economic-based metric of annual monetary expenditures for purchasing energy to a 
power-based metric of power expenditures for power production? In other words, if the economy spends one dollar on energy and produces produces ten dollars of output (e.g,. GDP), does the energy system output more or less than ten watts of power for every one watt it consumes to produce that output power?

The net external power ratio (direct energy inputs only, $N E P R_{\text {direct }}$ ) metric relates to annual operating energy inputs for power (e.g., energy/year) production, refining and distribution. Our metric using annual expenditures on energy, $\mathrm{NPR}_{\text {economic }}=f_{e, \mathrm{GDP}}^{-1}$, is also calculated using annual flows, but in this case, the flows are all of the annual monetary cost inputs or purchases for energy. Thus, it is valid to compare NEPR direct $_{\text {and NPR }}$ economic, since they are both measures of annual flows (e.g., power = energy/year).

In comparing these metrics, it is important to understand what we do and do not know about the underlying data. First, consider NPR economic and that we do not know how much profits are included in the underlying data for each country. One might assume that the underlying annual energy expenditures by consumers is greater than the annual operating costs of the producer, such that the energy system operates at a profit. However, we cannot verify this assumption for each year. In addition to operating costs, there are also energy-related capital investments each year (e.g., drilling oil wells, building pipelines). These capital costs can, but generally do not fully, affect prices in the same year because investors expect that capital to be repaid over several years to decades. In other words, capital costs in one year are amortized for several years afterward. In addition, the previous sentences somewhat assume that a market is governing the marginal price of an energy commodity, such that energy producers (eventually) respond to consumer feedback to produce what the consumer can afford. This assumption does not hold across all countries and commodities. Oil is traded on a global market, but coal, natural gas and electricity prices are often dictated by various local contracts, markets and regulations that do not guarantee that the energy operators operate at a profit at any given time.

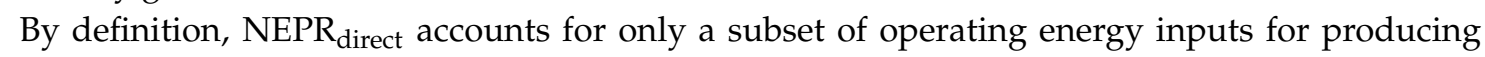
energy. It neglects any embodied energy (e.g., in units of energy) for operating costs, such as the salaries and services necessary to operate businesses that produce energy, which are theoretically included in NPR economic $_{\text {in units of money [37]. NEPR }}$ direct also neglects energy embodied in capital. On the other hand, NPR economic should include all annual operating expenses and some amortization of capital costs (e.g., customers usually pay regulated rates for electricity infrastructure, such as transmission and distribution). For these reasons, we hypothesize that $\mathrm{NPR}_{\text {economic }}<\mathrm{NEPR}_{\text {direct. }}$. Furthermore, from Part 1, we showed how NPR < NEPR for a simplified life cycle of a coal-fired power plant [1]. Thus, we ask the question as indicated by the Inequality (7).

$$
\frac{\mathrm{NPR}_{\text {economic }}}{\mathrm{NEPR}_{\text {direct }}} \sim \frac{f_{e, \mathrm{GDP}}^{-1}}{\mathrm{NEPR}_{\text {direct }}}<1 \quad ?
$$

The results plotted in Figure 7 indicate the following takeaways:

- for our data, Inequality (7) is not generally true over the studied time period,

- including more countries, particularly net energy exporters, in the analysis decreases the $\mathrm{NPR}_{\text {economic }} / \mathrm{NEPR}_{\text {direct }}$ ratio moving it closer to affirming our hypothesis in Inequality (7),

- using the data from the World Input-Output Database (three-sector energy-related intermediate expenditures plus capital expenditures as gross capital formation) decreases the $\mathrm{NPR}_{\text {economic }} / \mathrm{NEPR}_{\text {direct }}$ ratio, moving it closer to affirming our hypothesis in Inequality (7) and,

- the temporal pattern is driven primarily by variation in monetary expenditures for energy and not the calculation of NEPR direct.

First, we discuss the results using the IEA data to calculate $\mathrm{NPR}_{\text {economic }} \sim f_{e, \mathrm{GDP}}^{-1}$. For the time period in which data exist for all 44 countries (1980-2010), Inequality (7) holds during 1980-1985 
and 2008 (black line in Figure 7). The NPR economic $/ \mathrm{NEPR}_{\text {direct }}$ ratio is also $<1.1$ for $1987-1990$ and 2010. We repeat the calculation of the ratio using different subsets of our 44 countries to compare our calculations of expenditures for energy, $f_{e, \mathrm{GDP}}$, to our approximations using the World Input-Output Database (WIOD).

The 26-country series represents the longest continuous IEA time series (1978-2010) with a consistent set of countries. We create the 23-country calculation to compare results using expenditures on energy from IEA versus the WIOD, as there are only 23 countries that have requisite data in both our IEA data and the WIOD. The 28-country data series uses energy expenditures data from the WIOD for countries that are in our IEA dataset, but the WIOD data begin only in 1995. Most of the countries removed to create the 23- and 26-country data series are Asian countries and energy exporters. Thus, the 23- and 26-country sets primarily represent trends of OECD and Western economies. Removing exporting countries lowers the aggregate NEPR $_{\text {direct }}$ (see Figure 8 ) and, thus, causes the ratio of Figure 7 to rise.

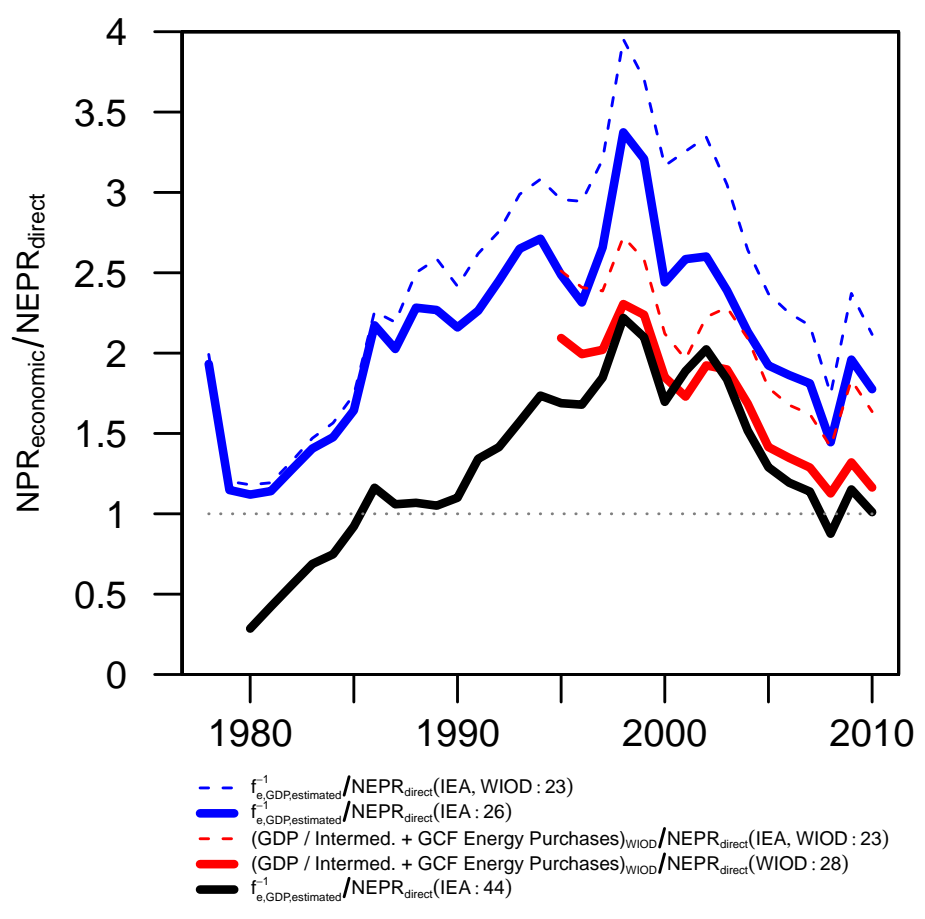

Figure 7. Five calculations of the same ratio show similar trends, but different magnitudes. The plotted lines are the ratio of $\mathrm{NPR}_{\text {economic }} \sim f_{e, \mathrm{GDP}}^{-1}$ (a monetary-based power return ratio metric) to NEPR direct (a purely energy-based PRR using annual power flows). WIOD: World Input-Output Database. (IEA,WIOD:23): the United States, the United Kingdom, Spain, the Netherlands, Japan, Italy, Germany, Canada, France, Austria, Denmark, Finland, Sweden, Australia, Belgium, Czech Republic, Greece, Hungary, South Korea, Mexico, Poland, Portugal and Turkey. (IEA: 26) = (IEA,23) countries plus Norway, New Zealand and Switzerland. (WIOD:28) $=($ IEA,23) countries plus Brazil, China, India, Indonesia and Russia. (IEA: 44) = calculations use data for all 44 countries in the IEA dataset. 

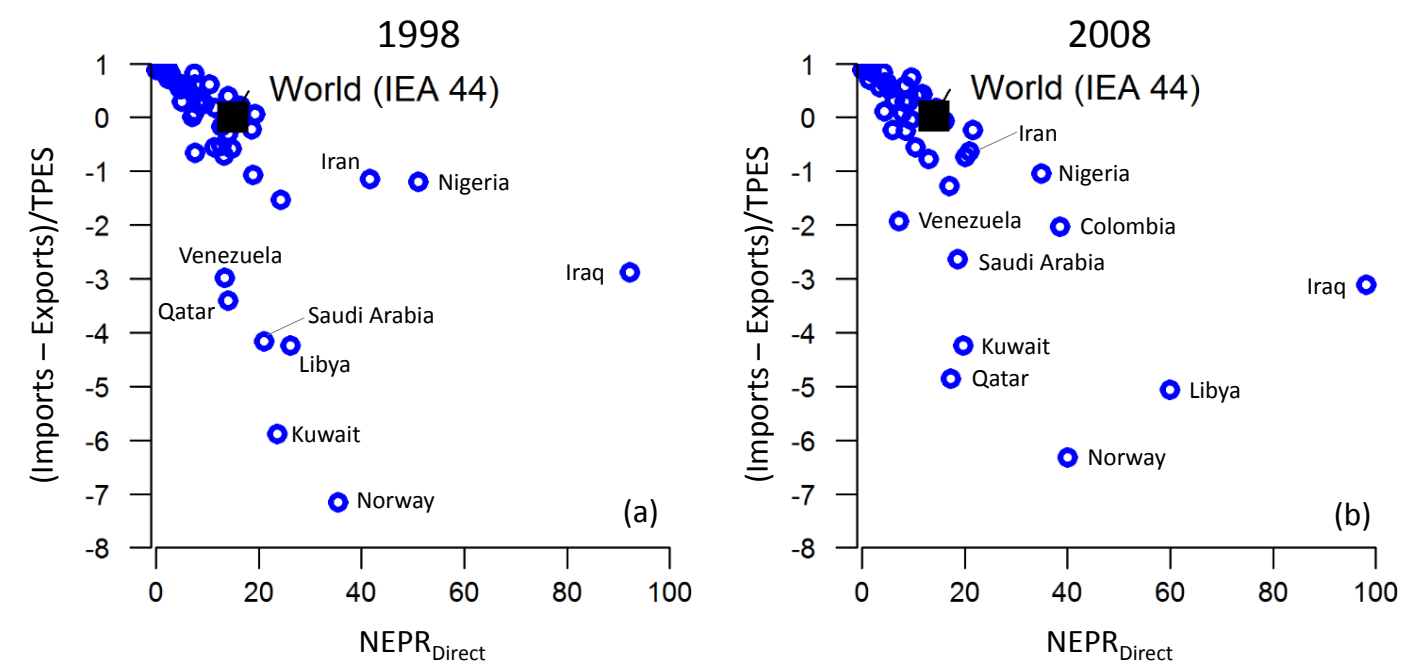

Figure 8. Countries that are net energy importers have lower NEPR direct. Data are shown for two years: (a) 1998, the year of the least expensive energy in the data; and (b) 2008, a year with relatively expensive energy. The $y$-axis indicates the ratio of net energy imports (in units of energy) divided by total primary energy supply (TPES). The large square represents the value for the 44-country world aggregate. Exports are assumed as a positive number, such that net (energy) exporting countries have negative values on the $y$-axis and net importing countries have positive values on the $y$-axis.

When analyzing the subset of 23 and 26 countries using our IEA-based calculations for $\mathrm{NPR}_{\text {economic, }}$ the ratio in Inequality $(7)$ is greater than one for all years and is lowest $(<1.2)$ in 1980 and 1981. Our calculation using the WIOD expenditures data and 28 countries (red solid line) closely follows the result for the 44-country aggregate. This (WIOD: 28) comparison returns a ratio $>1$ for all years and $<1.2$ for 2008 and 2010, which are the only two years in the WIOD with energy expenditures comparable to the late 1970s and early 1980s. When considering WIOD-based energy expenditures using the 23 countries that are in both the IEA data and WIOD, the ratio of NPR economic $/ \mathrm{NEPR}_{\text {direct }}$ reaches a minimum of 1.4 in 2008.

It is perhaps a coincidence that the 28-country WOID-based calculation closely matches the 44-country IEA-based calculation. However, the consistency of the fluctuations and general downward trend since 1995 indicate that our use of the WIOD data is appropriate. The intermediate energy expenditures (not including capital formation) for the 28-country subset as approximated from the WIOD are $13 \%-60 \%$ higher (usually $20 \%-40 \%$ higher) than expenditures using our IEA calculation for the same 28 countries. Thus, our energy expenditure approximation from the WIOD might contribute a non-trivial quantity of expenditures for non-energy goods and services (e.g., water supply). Future research can refine this calculation. For the WIOD 28-country subset, the inclusion of annual gross capital formation increases annual expenditures by $3 \%-5 \%$ per year relative to the intermediate expenditures. Nonetheless, including annual capital expenditures drives the $\mathrm{NPR}_{\text {economic }}$ higher and will move Inequality (7) closer to being true.

Analyzing more countries reduces the calculated ratio, providing a trend that is consistent with our hypothesis that $\mathrm{NPR}_{\text {economic }} / \mathrm{NEPR}_{\text {direct }}<1$. When using the IEA expenditures for energy, the 44-country ratio is less than the 26-country ratio, which is again less than the 23-country ratio. When using WIOD data for expenditures for energy, the 28-country calculated ratio is smaller than that using only the 23-country subset. This result should be expected in that the major factor in moving from $23 / 26 / 28$ countries to 44 is the inclusion of the major oil and gas net exporting countries. The energy-exporting countries have higher NEPR direct, and net importers of energy tend to produce energy at lower power return ratios (see Section 4.3). Thus, as more of the net exporting world is included, the aggregate NEPR direct will increase, and the ratio in Inequality (7) will decrease. However, one should not blindly assume that including more countries always 
decreases the NPR $R_{\text {economic }} / \mathrm{NEPR}_{\text {direct }}<1$ ratio, as the results very much depend on the specific countries included.

That the 44-country Inequality (7) holds for times when energy is relatively expensive might indicate an important limitation or feedback for the economy in terms of its ability to leverage energy. That is to say, a relatively fast-growing economy, possibly living off of past energy infrastructure investments, might be characterized as when Inequality (7) is not true, or when $\frac{\mathrm{NPR}_{\text {economic }}}{\mathrm{NEPR}_{\text {direct }}}=$ $\frac{f_{e, \mathrm{GD}}^{-1}}{\mathrm{NEPP}_{\text {direct }}}>1$. Accordingly, a slow-growing, recovering or shrinking economy might be characterized by $\frac{\mathrm{NPR}_{\text {economic }}}{\mathrm{NEPR}_{\text {direct }}}=\frac{f_{e, \mathrm{CDP}}^{-1}}{\mathrm{NEPR} \text { direct }} \leq 1$. Yet another implication of $\frac{\mathrm{NPR}_{\text {economic }}}{\mathrm{NEPR}_{\text {direct }}} \leq 1$ could be that there are resources with high NEPR $\mathrm{N}_{\text {direct }}$ to which the economy has yet to take advantage (e.g., an agrarian economy that first makes use of coal and steam engines). It is left to further research to determine how to use this ratio as a metric to measure or model the state of the economy as it relates to energy production.

Aside from the fact that the comparative metrics in Inequality (7) and Figure 7 are based on different units (numerator based on money/year and denominator based on energy/year), there are other reasons why Inequality (7) might not hold true for all years. One reason is that there are time lags in energy production relative to energy system investments. Energy production, sales and expenditures (e.g., $\mathrm{NPR}_{\text {economic }}$ ) are based on current year production, consumption and prices, but are also dependent on past investments. EIOU, and thus NEPR direct, however, is linked to both current and future energy production flows. That is to say, if one invests energy and money today (e.g., drilling an oil well), this is largely to produce future energy and revenues (e.g., oil flows from the well for many years after capital expenditure). The corollary is that energy production today is a result of past investments. This difficulty is not specific to the calculation of net energy metrics. A single project monetary return on investment must also consider the estimated cash flows over the entire project lifetime. Thus, comparing full life cycle cash and energy flows is one useful method for translating between individual ERRs and costs (see Part $1[1,37]$ ), but more difficult to extract from broader energy and economic time series.

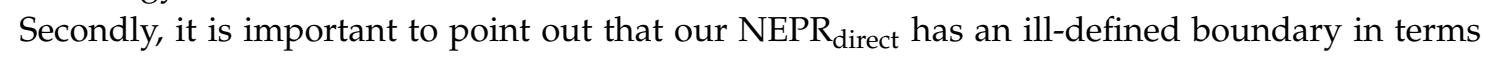
of including energy production as both primary energy (e.g., crude oil, NG and coal) and final consumed energy carriers (e.g., electricity from renewables and nuclear). It is also uncertain if the EIOU data are consistently reported across countries and parts of the life cycle or supply chain. Are countries actually reporting the same type of data? Finally, there are perhaps poor quality data in general, and including the purchases of energy carriers (e.g., gasoline) as intermediate energy input for energy production would lower the IEA-based calculation of $f_{e, \mathrm{GDP}}^{-1}$ in Inequality (7). However, this last caveat is somewhat checked by the red line of Figure 7 representing $\mathrm{NPR}_{\text {economic,WIOD }}$ using the WIOD data that should include all energy sector purchases: primary energy, energy carrier and non-energy goods and services. This comparison using the WIOD data includes only 23 countries with comparable data across both the IEA and WIOD datasets. For these 23 countries, the total intermediate expenditures and gross capital formation from the three energy sectors of the WIOD are greater than energy-only expenditures, $f_{e, \mathrm{GDP}}$, for the same countries. Thus, $\mathrm{NPR}_{\text {economic,WIOD }} / \mathrm{NEPR}_{\text {direct }}<\mathrm{NPR}$ economic,IEA $/ \mathrm{NEPR}_{\text {direct }}$ (dashed red line is below dashed blue line in Figure 7), as we should expect.

\subsection{Relation between Net Energy Imports and NEPR direct}

Here, we briefly investigate the relationship between importing energy and the net energy (or power) of producing energy in a country. As we discussed in Part 1 of this series [1], ERRs and PRRs are inversely related to costs and prices, respectively. Thus, a reasonable hypothesis is that countries with lower ERR and PRR energy production also have higher cost production. Further, countries with higher cost production might tend to import lower priced energy rather than produce domestically. 
The relationship between higher $\mathrm{NEPR}_{\text {direct }}$ and higher net exports is understandable. If a country can both produce energy at a high rate of production relative to inputs, and the country has a large reserve of this energy resource, the odds are good that the country can and will export that resource for profit (e.g., at lower cost than the marginal supply). Likewise, we might expect a country with relatively high energy imports to have a lower NEPR $R_{\text {direct. }}$. It makes greater economic sense to import higher ERR ( lower cost) and PRR ( lower price) foreign energy than to produce lower ERR ( $\sim$ higher cost) and PRR ( higher price) domestic energy. For example, the U.S. is a moderate net energy importer (almost completely for crude oil only) with NEPR direct between seven and 11; Japan is a major net energy importer with $\mathrm{NEPR}_{\text {direct }}<3$ since 1968; and Norway is a net energy exporter with NEPR direct $>20$ since 1974. It is also possible that countries with one high NEPR energy resource can internally consume that resource in order to produce a lower NEPR resource for larger export sales (e.g., Canada burning domestic natural gas to produce oil sands bitumen/syncrude for export).

Figure 8 plots country import ratios versus NEPR $_{\text {direct }}$ for two years. The results in Figure 8 support the hypothesis at the beginning of this subsection. We show only two years: 1998 as the year with the least expensive oil price, and 2008 as a year with expensive energy overall. One conclusion from this analysis is that the patterns in Figure 8 are not qualitatively different, because the other years show similar patterns.

Even though NEPR direct represents a small fraction of the embodied energy investment (or inputs), all net importing countries have NEPR direct $<20$. The world data point (black square) indicates that our calculation of net imports for the 44-country aggregate is near zero (as one should

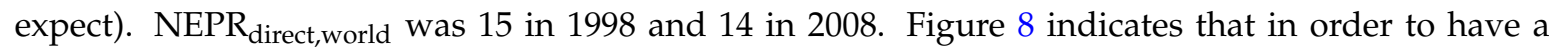
complete view of the world economy, it is necessary to calculate metrics at the scale of the world economy. In other words, the NEPR direct,world is not obvious from looking at the NEPR direct for each country. One additional takeaway from Figure 8 is that there are more countries composing a much higher total population that is leveraging the high NEPR direct (or EROI) of a smaller set of exporting countries with a smaller aggregate population.

\section{Conclusions}

Our calculation of expenditures on ( $\sim$ primary) energy expressed as a fraction of GDP, $f_{e, \mathrm{GDP}}$, declined almost continuously from 1980 (10.3\% of GDP) to 1998 (3.0\% of GDP) and then rose almost continuously from $1998-2008$ (8.1\% of GDP). From the energy analysis viewpoint, the net power of the world economy generally rises from 1980-1998, then declines until 2008 and then slightly rebounds to 2010. This trend is indicated by our estimate of the economy-wide economic net power ratio, $\mathrm{NPR}_{\text {economic }}=f_{e, \mathrm{GDP}}^{-1}$. The expenditures for oil usually dominate the overall expenditures on energy at an average of $45 \%$ of the total, ranging from $29 \%$ in 1998 to $68 \%$ in 1979 .

For any given time period, we believe this $\mathrm{NPR}_{\text {economic }}$ might be the most practical metric of the energy return on investment (EROI), or more specifically, net power, of an economy (country or the world). We also revealed an interesting insight by comparing our money-based economic net power ratio, $\mathrm{NPR}_{\text {economic, }}$ to the energy-based biophysical metric of net external power ratio, or NEPR $_{\text {direct }}$ (NEPR is equivalent to EROI as calculated using time series data in much of the literature).

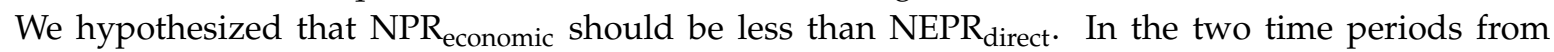
1980-2010 when the global NPR economic $_{\text {was below or nearly equal to the NEPR }}$ direct, the world was in a relatively low growth or recessionary state. Thus, the ratio of NPR economic to NEPR direct $_{\text {ic }}$ provides a combined economic and biophysical perspective to indicate if the economy is sufficiently leveraging the energy subsystem of the economy. When this ratio is high, the economy might be 'over-consuming' based on past productive energy investments, and when the ratio is low, it might indicate the remaining potential for increased investments in energy-consuming activities.

We also showed that there is a clear trend indicating that net energy exporting countries tend to produce energy at high net energy, typically $\mathrm{NEPR}_{\text {direct }}>20$, while net energy importing countries tend to produce energy at lower net energy, NEPR direct $<20$. While there is no clear boundary, 
this finding presents an important concept for future research to incorporate into energy-economic modeling and projections. We hope that the insights of this paper, together with future modeling efforts, will further the translations between net energy and economic analyses and data, such that we enable a more holistic viewpoint to interpret the past and future roles of fossil, renewable and low-carbon energy.

Acknowledgments: This work was partially supported by, and the authors thank, the Jackson School of Geosciences Energy Theme at The University of Texas at Austin. An IEA representative informed us that they could not comment on the full methodology for our calculations of expenditures on energy, but we acknowledge IEA assistance in ensuring that we had the appropriate documentation and interpretations of data.

Author Contributions: Carey W. King designed and structured the research.Alyssa Donovan, John P. Maxwell and Carey W. King obtained and organized the data from the various sources while performing calculations for the paper.

Conflicts of Interest: The authors declare no conflict of interest.

\section{References}

1. King, C.W.; Maxwell, J.P.; Donovan, A. Comparing world economic and net energy metrics, Part 1: Price Perspective. Energies 2015, 8, 12949-12974.

2. King, C.W. Comparing world economic and net energy metrics, Part 3: Macroeconomic Historical and Future Perspectives. Energies 2015, 8, 12997-13020.

3. Solow, R. A Contribution to the Theory of Economic-Growth. Q. J. Econ. 1956, 70, 65-94.

4. Hamilton, J. Historical Oil Shocks. In Routledge Handbook of Major Events in Economic History; Parker, R.E., Whaples, R.M., Eds.; Routledge: New York, NY, USA, 2013; p. 239265.

5. Ayres, R.; Voudouris, V. The economic growth enigma: Capital, labour and useful energy? Energy Policy 2014, 64, 16-28.

6. Voudouris, V.; Ayres, R.; Serrenho, A.C.; Kiose, D. The economic growth enigma revisited: The EU-15 since the 1970s. Energy Policy 2015, 86, 812-832.

7. Kander, A.; Stern, D.I. Economic growth and the transition from traditional to modern energy in Sweden. Energy Econ. 2014, 46, 56-65.

8. Kümmel, R. The Second Law of Economics: Energy, Entropy, and the Origins of Wealth; Springer: Berlin, Germnay, 2011.

9. Hall, C.A.S.; Klitgaard, K.A. Energy and the Wealth of Nations: Understanding the Biophysical Economy, 1st ed.; Springer: Berlin, Germnay, 2012.

10. Ayres, R.U. Sustainability economics: Where do we stand? Ecol. Econ. 2008, 67, 281-310.

11. Brown, J.H.; Burnside, W.R.; Davidson, A.D.; Delong, J.R.; Dunn, W.C.; Hamilton, M.J.; Mercado-Silva, N.; Nekola, J.C.; Okie, J.G.; Woodruff, W.H.; et al. Energetic Limits to Economic Growth. BioScience 2011, 61, 19-26.

12. Peters, G.P.; Hertwich, E.G. $\mathrm{CO}_{2}$ embodied in international trade with implications for global climate policy. Environ. Sci. Technol. 2008, 42, 1401-1407.

13. Acemoglu, D.; Robinson, J.A. Why Nations Fail: The Origins of Power, Prosperity, and Poverty; Crown Business: New York, NY, USA, 2012.

14. Tainter, J. The Collapse of Complex Societies; Cambridge University Press: Cambridge, UK, 1988.

15. Tainter, J.A. Energy, complexity, and sustainability: A historical perspective. Environ. Innov. Soc. Transit. 2011, 1, 89-95.

16. Tainter, J.A. Energy and Existential Sustainability: The Role of Reserve Capacity. J. Environ. Account. Manag. 2013, 1, 213-228.

17. Turchin, P.; Nefedov, S.A. Secular Cycles; Princeston University Press: Princeton, NJ, USA, 2009.

18. Ayres, R.U.; Warr, B. Accounting for growth: The role of physical work. Struct. Chang. Econ. Dyn. 2005, $16,181-209$.

19. Stern, D.; Kander, A. The Role of Energy in the Industrial Revolution and Modern Economic Growth. Technical Report; The Australian National University: Canberra, Australia, 2011.

20. Stern, D.I.; Kander, A. The Role of Energy in the Industrial Revolution and Modern Economic Growth. Energy J. 2012, 33, 125-152. 
21. Hamilton, J. Causes and Consequences of the Oil Shock of 2007-08. In Brookings Papers on Economic Activity; Romer, D., Wolfers, J., Eds.; Brookings Institution Press: Washington, DC, USA, 2009; p. 69.

22. Hall, C.A.S.; Cleveland, C.J.; Kaufmann, R.K. Energy and Resource Quality: The Ecology of the Economic Process; Wiley: New York, NY, USA, 1986.

23. Hall, C.A.S.; Balogh, S.; Murphy, D.J.R. What is the Minimum EROI that a Sustainable Society Must Have? Energies 2009, 2, 25-47.

24. King, C.W. Energy intensity ratios as net energy measures of United States energy production and expenditures. Environ. Res. Lett. 2010, 5, 044006.

25. Brandt, A.R. Converting oil shale to liquid fuels: Energy inputs and greenhouse gas emissions of the Shell in situ conversion process. Environ. Sci. Technol. 2008, 42, 7489-7495.

26. Brandt, A.R. Converting Oil Shale to Liquid Fuels with the Alberta Taciuk Processor: Energy Inputs and Greenhouse Gas Emissions. Energy Fuels 2009, 23, 6253-6258.

27. Brandt, A.R.; Englander, J.; Bharadwaj, S. The energy efficiency of oil sands extraction: Energy return ratios from 1970 to 2010. Energy 2013, 55, 693-702, doi:10.1016/j.energy.2013.03.080.

28. Guilford, M.C.; Hall, C.A.S.; O'Connor, P.; Cleveland, C.J. A New Long Term Assessment of Energy Return on Investment (EROI) for U.S. Oil and Gas Discovery and Production. Sustainability 2011, 3, 1866-1887.

29. Farrell, A.E.; Plevin, R.J.; Turner, B.T.; Jones, A.D.; O'Hare, M.; Kammen, D.M. Ethanol can contribute to energy and environmental goals. Science 2006, 311, 506-508.

30. Raugei, M.; Fullana-i-Palmer, P.; Fthenakis, V. The energy return on energy investment (EROI) of photovoltaics: Methodology and comparisons with fossil fuel life cycles. Energy Policy 2012, 45, 576-582, doi:10.1016/j.enpol.2012.03.008.

31. Dale, M.; Benson, S.M. Energy Balance of the Global Photovoltaic (PV) Industry-Is the PV Industry a Net Electricity Producer? Environ. Sci. Technol. 2013, 47, 3482-3489. Available online: http://pubs.acs.org/ doi/pdf/10.1021/es3038824 (accessed on 3 March 2015).

32. Fthenakis, V.M.; Kim, H.C. Photovoltaics: Life-cycle analyses. Sol. Energy 2011, 85, 1609-1628.

33. Zhang, Y.; Colosi, L.M. Practical ambiguities during calculation of energy ratios and their impacts on life cycle assessment calculations. Energy Policy 2013, 57, 630-633.

34. Bullard, C.W., III; Herendeen, R.A. The energy cost of goods and services. Energy Policy 1975, 3, 268-278, doi:10.1016/0301-4215(75)90035-X.

35. Costanza, R. Embodied Energy and Economic Valuation. Science 1980, 210, 1219-1224.

36. King, C.W.; Hall, C.A.S. Relating Financial and Energy Return on Investment. Sustainability 2011, 3, 1810-1832.

37. Henshaw, P.F.; King, C.; Zarnikau, J. System Energy Assessment (SEA), Defining a Standard Measure of EROI for Energy Businesses as Whole Systems. Sustainability 2011, 3, 1908-1943.

38. Miller, R.E.; Blair, P.D. Input-Output Analysis: Foundations and Extensions; Cambridge University Press: Cambridge, UK, 2009.

39. Casler, S.; Wilbur, S. Energy Input-Output Analysis: A Simple Guide. Resour. Energy 1984, 6, $187-201$.

40. Bullard, C.W.; Penner, P.S.; Pilati, D.A. Net energy analysis: Handbook for combining process and input-output analysis. Resour. Energy 1978, 1, 267-313.

41. King, C.W. Matrix method for comparing system and individual energy return ratios when considering an energy transition. Energy 2014, 72, 254-265.

42. Brandt, A.R.; Dale, M.; Barnhart, C.J. Calculating systems-scale energy efficiency and net energy returns: A bottom-up matrix-based approach. Energy 2013, 62, 235-247.

43. Brandt, A.R.; Dale, M. A General Mathematical Framework for Calculating Systems-Scale Efficiency of Energy Extraction and Conversion: Energy Return on Investment (EROI) and Other Energy Return Ratios. Energies 2011, 4, 1211-1245.

44. Murphy, D.J.R.; Hall, C.A.S.; Dale, M.; Cleveland, C.J. Order from Chaos: A Preliminary Protocol for Determining EROI for fuels. Sustainability 2011, 3, 1888-1907.

45. Modahl, I.S.; Raadal, H.L.; Gagnon, L.; Bakken, T.H. How methodological issues affect the energy indicator results for different electricity generation technologies. Energy Policy 2013, 63, 283-299.

46. Herendeen, R.A. Connecting net energy with the price of energy and other goods and services. Ecol. Econ. 2015, 109, 142-149. 
47. Timmer, M.P.; Dietzenbacher, E.; Los, B.; Stehrer, R.; de Vries, G.J. An Illustrated User Guide to the World Input-Output Database: The Case of Global Automotive Production. Rev. Int. Econ. 2015, 23, 575-605.

48. O'Mahony, M.; Timmer, M.P. Output, Input and Productivity Measures at the Industry Level: The EU KLEMS Database. Econ. J. 2009, 119, F374-F403.

49. Dietzenbacher, E.; Los, B.; Stehrer, R.; Timmer, M.; de Vries, G. The Construction of World Input-Output Tables in the WIOD project. Econ. Syst. Res. 2013, 25, 71-98.

50. Sorrell, S.; Speirs, J. Using growth curves to forecast regional resource recovery: Approaches, analytics and consistency tests. Philos. Trans. R. Soc. A Math. Phys. Eng. Sci. 2014, 372, doi:10.1098/rsta.2012.0317. Available online: http:/ / rsta.royalsocietypublishing.org/content/372/2006/20120317.full.pdf+html (accessed on 3 March 2015).

(C) 2015 by the authors; licensee MDPI, Basel, Switzerland. This article is an open access article distributed under the terms and conditions of the Creative Commons by Attribution (CC-BY) license (http:/ / creativecommons.org/licenses/by/4.0/). 